\title{
Inovasi Strategi Pemasaran Sentra Industri Brem Madiun Dalam Menghadapi Persaingan di Masa Pandemi Covid 19
}

\author{
Dian Citaningtyas Ari Kadi ${ }^{1 *}$; Rizal Ula Ananta Fauzi²; Kamal Ali Roziq ${ }^{3}$; Aji Pamungkas \\ Selly Andan Ria Rossanto
}

$\underline{\text { Published online: } 5 \text { July } 2021}$

\begin{abstract}
In the economy, the industrial sector has the most important role in our country. The existence of an industry can increase regional income and can create jobs. One of the industrial centres in Madiun is the industrial centre for making Brem, who does not know this particular dish. Brem is processed by fermentation of cooked glutinous rice and mixed with yeast which helps to produce a tape which then takes the water to make a brem. In the village of Bwisata Kec. Wonoasri Madiun is one of the centres in making the brem, one of which is Brem Candi Mas. And we make observations there. This program aims to add insight into MSMEs in Madiun Regency, especially in the Brem Candi Mas UMKM Center, increase sales and income so that they can survive the economic crisis caused by the Covid 19 pandemic, and create new marketing strategies. This service activity is assisted by students as entrepreneurial knowledge. The innovation made is helping the digital marketing process, namely through social media such as Instagram, Facebook, and we have created a website so that the current marketing process does not only depend on manual marketing from store to store but is more effective with online marketing.
\end{abstract}

Keyword: Marketing, online marketing, brem, instagram, facebook, website

\begin{abstract}
Abstrak. Dalam perekonomian sektor industri mempunyai peranan yang paling penting di negara kita ini. Keberadaan sebuah industri dapat meningkatkan suatu pendapatan daerah dan dapat membuka lapangan pekerjaan. Salah satu sentra industri yang berada di madiun adalah sentra industri pembuatan brem, siapa yang tidak mengenal panganan khas yang satu ini. Brem merupakan olahan dengan cara fermentasi beras ketan yang dimasak dan dalam pembuatannya di campur dengan ragi yang membantu agar menghasilakan sebuah tape yang selanjutnya diambil air nya untuk dijadikan sebuah brem. Di Desa Bancong Kec. Wonoasri Madiun adalah salah satu sentra dalam pembuatan brem tersebut, salah satunya adalah brem candi mas. Dan kita melakukan observasi disana. Progam ini bertujuan untuk menambah wawasan tentang UMKM di kabuoaten madiun khusunya di Centra UMKM Brem Candi Mas ini,meningkatkan penjualan dan pendapatan agar tetap bisa bertahan dalam krisis ekonomi akibat dari pandemi Covid 19,serta membuat strategi pemasaran yang baru. Kegiatan pengabdian ini dibantu oleh para mahasiswa sebagai pengetahuan berwirausaha. Inovasi yang dilakukan adalah membantu proses pemasaran digital yaitu melalui media sosial seperti instagram, facebook, dan kami buatkan website sehingga proses pemasaran dimasa saat ini tidak hanya bergantung pada pemasaran manual dari toko ke toko namun lebih efektif dengan pemasaran online.

Kata kunci: Marketing, pemasaran online, brem, instagram, facebook, website
\end{abstract}

\footnotetext{
${ }^{1-5}$ Universitas PGRI Madiun

*) corresponding author

Dian Citaningtyas Ari Kadi

Program Studi Manajemen Fakultas Ekonomi Dan Bisnis

Universitas PGRI Madiun

Email: citakirana11@gmail.com
}

\section{PENDAHULUAN}

Dalam perekonomian sektor industri mempunyai peranan yang paling penting di negara kita ini. Keberadaan sebuah industri dapat meningkatkan suatu pendapatan daerah dan dapat membuka lapangan pekerjaan serta mengurangi pengangguran 
(Purba, 1996). Terdapat beberapa UMKM yang berkembang di Madiun dan menjadi jajanan makanan khas Madiun yang diantaranya adalah BREM. Istilah brem ialah pemikiran/ filsafat masyarakat dahulu, yang dikaitkan dengan sejarah agama Hindu-Budha. Dulunya brem ini adalah sebuah cairan yang digunakan untuk pengganti darah dalam sebuah upacara adat masyarakat sekitar yang bertujuan untuk melestarikan manusia dengan lingkungan. Brem biasanya berbentuk lempengan balok putih atau sedikit kekuningan yang memiliki cita rasa manis dan sedikit asam.

Brem adalah salah satu jajanan tradisonal hasil fermentasi yang rasanya enak dan banyak digemari masyarakat. Terdapat 2 jenis olahan brem yaitu brem padat dan brem cair atau disebut juga brem bali. Brem padat dibuat atau diproses dengan mengolah air perasan tape ketan yang kemudian dimasak dengan cara merebus air tape tersebut, setelah selesai perebusan barulah mengaduk air tape sampai menjadi berubah warna dan mengental barulah proses pencetakan. Brem biasanya bewarna putih, tekstur tidak lembek dan mudah hancur jika kita memakanya. Dalam proses fermentasi tape biasanya membutuhkan waktu kurang lebih 38 hari pada suhu $30^{\circ} \mathrm{C}$.Apabila kita melakukan fermentasi tape selama 2 hari maka tape yang dihasilkan tekstur dari tape tersebut masih keras dan tidak manis. Dan jika proses fermentasi lebih dari 7 hari maka rasa tape yang dihasilkan akan sangat keras karena mulai terbentuk alkohol dan rasa yang dihasilkan akan sangat asam dan pasti tidak enak. (Djutikah et. Al. 1988).

Pada umumnya bahan yang digunakan dalam pembuatan brem padat adalah beras ketan selain beras ketan adalah pilihan bahan yang bisa digunakan dalam membuat brem padat, anatara lain tape singkong, umbi talas dan jenis umbi-umbian lainya. Pusat penghasil olahan brem ini pertama kali terdapat di sebuah kecamatan yang terletak di Caruban madiun dan terdapat 2 desa penghasil brem ini yaitu di desa bancong dan kaliabu. Brem sendiri mulai dibuat oleh nenek moyang dulu sebagai salah satu jenis makanan, waktu demi waktu hasil olahan tersebut mulai dikenal dan diminati oleh msyarakat sekitar sehingga menjadi sebuah mata pencarian penduduk sekitar untuk memenuhi kebutuhan hidupnya. Sampai saat ini brem sudah dikerjakan dari generasi ke generasi dan membuat brem menjadi sebuah simbol makanan khas dari kabupaten madiun sehingga banyak yang menjadikan brem oleh oleh untuk dibawa keluar kota (Fekodin, 2020). Contoh produk brem yang ada di madiun pada gambar dibawah ini:

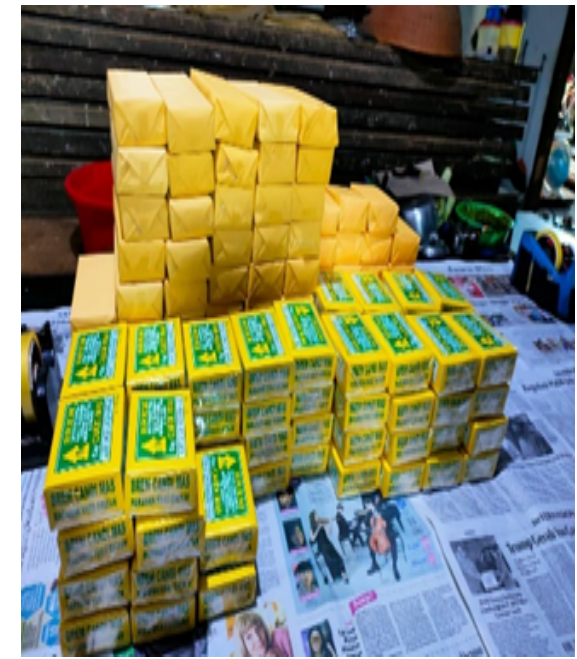

Gambar 1 Produk Brem Candi Mas

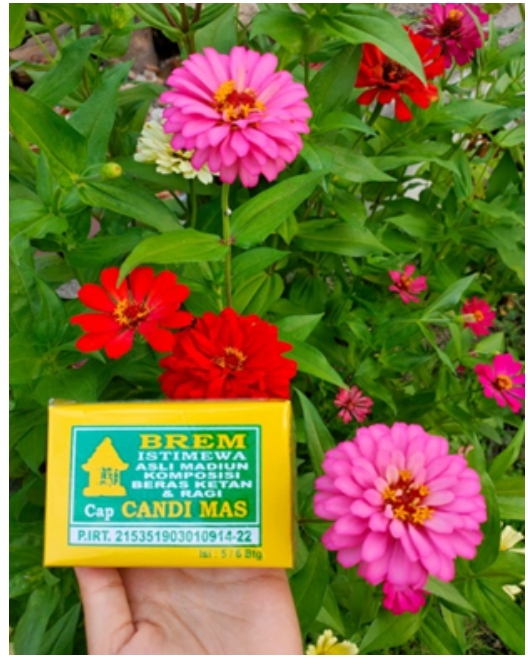

Gambar 2 Produk Brem Candi Mas

Banyak sekali manfaat yang bisa kita peroleh saat mengkonsumsi brem. Brem diyakini bisa menaikan kadar hormon yang dapat membantu arteri yang berlebih dan diyakini juga dapat mengurangi resiko serangan jantung. Brem juga dipercaya dapat memperlancar peredaran darah dalam tubuh dan bisa juga untuk menurukan kadar kolestrol dalam tubuh. (Novella Candra) Jajanan yang satu ini memang sangat terkenal di madiun dan sering dijadikan salah satu pilihan oleh-oleh wisatawan yang datang ke madiun. Di Desa Bancong tepatnya di Jln Mawar Rt/Rw 03/01 Wonoasri,Madiun merupakan salah satu tempat industri Brem, dengan adanya industri rumahan 
tersebut maka mampu menyangga perekonomian banyak elemen dan masyarakat sekitar.(Fekodin, 2020).

Kondisi pandemic yang ada telah menurunkan omset penjualan sehinngga diperlukan sebuah inovasi. Menurut Fauzi et al. (2020) Inovasi mampu memberikan nilai positif bagi pelaku UMKM. Inovasi diperlukan terutama dimasa new normal dengan melihat menurunnya minat konsumen maka dibutuhkan inovasi baru untuk meningkatkan ketertarikan konsumen dan mencari pangsa pasar baru Fauzi et al (2020). Umkm perlu mendapatkan modal dan menaikkan omset guna menjaga persaingan pasar. yang mana modal masih menjadi kendala bagi wirausaha dalam menjalankan usahanya (fauzi, 2021). Modal usaha dan laba dipengaruhi oleh penjualan yang terjadi. Semakin tinggi penjualan akan meningkatkan laba dan menambah modal produksi. Peran stategi pemasaran sangat menentukan penjualan bagi usaha Brem ini. Terutama pemasaran digital yang sangat mendukung pada masa pandemic ini.

\section{Kajian Pustaka}

Kunci dalam konsep pemasaran yang digunakan untuk mendapatkan tujuan dalam sebuah organisasi atau perusahaan haruslah yang efektif dibandingkan dengan pesaingnya. Hal ini juga bertujuan untuk menciptakan nilai pelanggan kepada sasaran pasar yang telah dipilih. Pemasaran berorientasi pada bagaimana pemilik bisnis atau perusahaan memenuhi kebutuhan dan kepuasan pelanggan (Fauzi,2019). Hal ini sesuai paper Armanet al (2020), dalam pemasaran online mempunyai banyak keuntungaan.

A. Konsep pemasaran.

1. Kebutuhan, keinginan, dan pemasaran

Kebutuhan adalah suatu hal yang dapat menggerakan manusia untuk mendapatkan suatu yang diperlukan untuk memenuhi kebutuhan tersebut. Sedangkan keinginan adalah hasrat yang dirasakan untuk memperoleh suatu kepuasan akan kebutuhan yang diharapkan (Agus, 2016). Dan permintaan adalah keinginan untuk memperoleh sebuah barang atau jasa yang didukung dengan kemampuan untuk membayar dan membeli.

2. Penawaran pasar - produk

Penawaran pasar merupakan gabungan antara produk, pelayanan dan juga informasi yang ditawarkan dalam pasar untuk memenuhi kebutuhan mereka.

3. Nilai pelanggan dan kepuasan

Nilai pelanggan dapat dilihat dari mutu, harga, dan jasa yang dapat menggambarkan manfaat dan biaya berwujud dan tidak berwujud bagi konsumen. Sedangkan kepuasan adalah nilai dari sebuah produk yang sesuai dengan diharapkan dari kinerja seseorang.

4. Pertukaran dan hubungan pertukaran

Adalah suatu tindakan yang dilakukan untuk mendapatkan objek yang diinginkan dari seseorang dengan memberikan sebuah penawaran sebagai imbalan. Arlina (2016) Pemasaran itu sendiri terdiri dari berbagai tindakan yang digunakan untuk memelihara sebuah hubungan antara produsen dan konsumen melalui berbagai macam bentuk transaksi dengan targetnya adalah pembeli, pemasok, dan penyalur yang melibatkan sebuah produk, ide, dan lain sebaginya didalamnya.

\section{Pasar}

Merupakan tempat dimana penjual dan pembeli yang memiliki potensial berkumpul untuk memenuhi suatu kebutuhan atau keinginan mendapatkan sebuah produk atau jasa yang dapat ditukarkan untuk memuaskan kebutuhan dan keinginan. 


\section{B. Media Sosial}

Media sosial merupakan media berbagi dan berinteraksi dengan kecanggihan teknologi tanpa dibatasi ruang dan waktu. Media sosial sangat membantu dan memudahkan para penggunanya berkomunikasi dan lain-lain. Media sosial bisa berbagi berbagai bentuk, seperti majalah, forum internet, foto, video. Dalam peper fauzi et, al. (2021) Digital Marketing merupakan suatu proses perencanaan dan pelaksanaan dari konsep, ide, harga, promosi dan distribusi.

\section{Facebook}

Facebook merupakan layanan jejaring sosial berkantor pusat di Menlo Park, California, Amerika Serikat yang diluncurkan pada bulan Februari 2004. Per September 2012, Facebook memiliki lebih dari satu miliar pengguna aktif, lebih dari separuhnya menggunakan telepon genggam. Selain itu, pengguna dapat bergabung dengan grup pengguna dengan ketertarikan yang sama, diurutkan berdasarkan tempat kerja, sekolah atau perguruan tinggi, atau ciri khas lainnya, dan mengelompokkan teman-teman mereka kedalam daftar seperti "Rekan Kerja atau Teman Dekat. (https://id.m.wikipedia.org/wiki/Facebook\#). Bagi pelaku usaha Facebook berdampak baik untuk proses promosi. Tentu hal ini menambah nilai positive bagi pelaku usaha karena bisa digunakan untuk mempromosikan produk yang dijual dan juga bisa langsung berinteraksi dengan pelanggan.

\section{Instagram}

Instagram merupakan aplikasi berbagi foto maupun video. Instagram memiliki kelebihan dari Facebook terutama pada fitur pencarian yang memungkinkan pengguna untuk mengakses semua hal. Karena sangat banyak penggunanya dan mudah untuk diakses, disinilah peran Instagram menarik konsumen menjadi sangat penting. Selain mempromosikan menggunakan konten artikel, para pengguna bisnis online juga memanfaatkan gambar sebagai media pemasaran sehingga sangat tepat jika pemasaran melalui Instagram karena lebih diketahui banyak orang.

\section{Internet Marketing}

Internet marketing adalah suatu bentuk usaha yang dilakuakan oleh perusahaan untuk memasarkan produk atau jasanya sekaligus untuk membangun sebuah hubungan dengan pelanggannya melalui media internet. Internet marketing yaitu usaha perusahaan dalam menjalin hubungan dengan konsumen melalui media internet untuk mepromosikan barang dan jasanya Konsumen yang mencari informasi atau bahkan melakukan transaksi pembelian melalui intenet disebut dengan online customer. Menurut Hoffman \& Novak (1996) online customer ternyata memiliki motivasi yang berbeda dalam memanfaatkan informasi yang didapat melalui internet. Sebagian konsumen memanfaatkan internet hanya untuk mencari produk atau jasa, ada juga yang menggunakannya untuk navigasi informasi dan pengalaman dari konsumen lainnya.

\section{METODE PELAKSANAAN}

Kegiatan pengabdian ini dilakukann selama 6 minggu dilakukan pada bulanNovember sampai dengan Desember 2020. Pengabdian ini lakukan di UMKM di centra perusahaan brem Cap "Candi mas" yang berlokasi di Desa Bancong Jl. Mawar rt 03 rw 01, Wonoasri, Kabupaten Madiun. Ada beberapa tahap yang dilakukan dalam kegiatan dapat dilihat pada tabel 1.

\section{Tahap survei}

Pada tahap ini melakukan survey lokasi yang cocok untuk melakukan pengabdian masyarakat.

Dari beberapa UMKM yang telah ditemui, usaha Brem Bu Fekodin ini menjadi pilihan dalam kegiatan pengabdian masyarakat ini. 


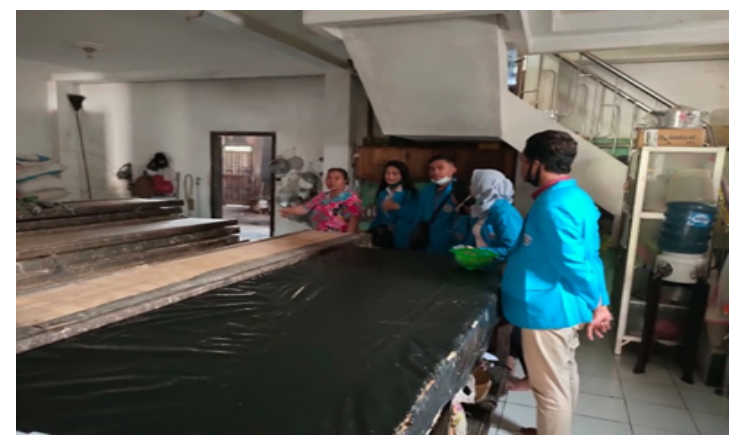

Gambar 3 Survei UMKM Brem Candi Mas

2. Tahap analisis permasalahan

Setelah pemilihan tempat pengabdian masyarakat yang cocok, kami berusaha mengalisis permasalah yang pokok pada UMKM Brem Candi mas.

Tabel 1.

Jadwal dan tahapan pelaksanaan

\begin{tabular}{llllllll}
\hline \multirow{2}{*}{ No. } & \multicolumn{5}{c}{ Kunjungan Ke } \\
\cline { 3 - 5 } & \multicolumn{1}{c}{ Nama Kegiatan } & I & II & III & IV & V & VI \\
\hline 1 & Survei UMKM & & & & \\
\hline 2 & Analisis Permasalahan & & & & \\
\hline 3 & Perencanaan dan menyiapkan kebutuhan & & & \\
\hline 4 & Proses produksi dan pemasaran & & & \\
\hline 5 & Pengembangan produk brem & & & \\
\hline 6 & Laporan pengabdian & & & \\
\hline
\end{tabular}

\section{Tahap perencanaan}

Dari permasalahan yang ditemukan pada UMKM Brem bu Fekodin, kami berusaha untuk memberikan solusi dan inovasi untuk meningkatkan penjualan dan berkembangnya produk UMKM Brem Candi Mas Pada masa Pandemi. Kami mencoba untuk membuat akun website selain itu kami juga akan menggunakan media sosial seperti Instagram dan Facebook dalam proses marketingnya.

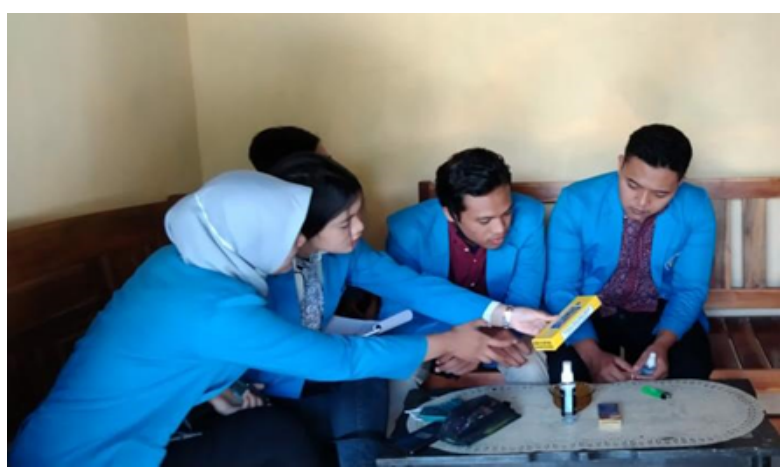

Gambar 4 Perencanaan

\section{Tahap Pemasaran}

Pada tahap ini kami ikut serta dalam proses Marketing Online, kami mencoba untuk memasarkan produk brem ini melalui web, instagram, dan facebook yang tujuan nya agar umkm brem ini dapat dikenal oleh masyarakat umum.

5. Tahap pengembangan produk/Inovasi

Pengembangan produk kerupuk dilakukan dengan cara pemberian inovasi, terkait dengan pemasaran yang baik dan berkualitas membantu memasarkan produk yang lebih luas melalui media sosial dan website. 


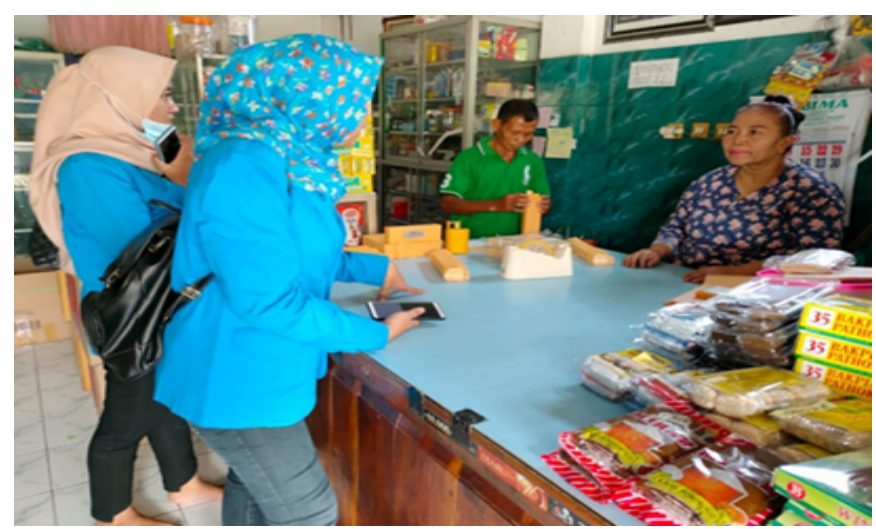

Gambar 1 Pengembangan dan pemberian Inovasi

6. Tahap pembuatan laporan

Tahap ini merupakan tahap akhir dari kegiatan abdimas, Dimana pada tahap ini kami membuat laporan pembuatan tentang centra umkm brem ini.

\section{HASIL DAN PEMBAHASAN}

Pada tahap ini kami menawarkan pemasaran digital melalui website dan endorsment di sosial media terhadap produkbrem agar pemasaran dimasa pandemi ini bisa stabil dan tidak hanya mengandalkan pemasaran melalui toko namun juga lewat sosial media. Inivasi yang kami berikan yaitu melalui:

1. Website

Kami memilih membuat website untuk memasarkan produk karena lebih memudahakn pembeli untuk mengetahui produk apa saja yang kami sediakan serta informasi tentang Centra UMKM Brem Candi Mas ini lebih banyak. Selain itu, pembeli dapat langsung memilih produk apa saja yang diinginkan kemudian membayarnya melalui transfer bank, dan menunggu produk yang dibeli dikirim oleh penjual tanpa harus repot untuk datang ke toko. Tingginya minat masyarakat terhadap akses internet yang lebih cepat membuat WiFi menjadi suatu hal yang penting di kalangan masyarakat modern (fauzi, 2017)

\section{Endorsement}

Salah satu kunci sukses dalam pemasaran digital adalah dengan melakukan endorsment ke berbagai akun media sosial yang dianggap memiliki insight yang cukup tinggi sehingga produk yang diendorse bisa menjangkau lebih banyak akun. Dalam melakukan endorsement kami memiliki berbagai tahapan:

\section{a. Research}

Sebelum melakukan endorsement, kami memilih beberapa akun yang membuka endorse dan memilih yang memiliki insight cukup tinggi. Tentu saja akun yang kami pilih lebih tepatnya adalah akun-akun yang membuka endorsement produk makanan. Dalam hal ini kami memilih endorsement melalui akun instagram dan facebook. menurut Syafaruddin Z, Suharyono, (2016) dalam Kadi et al (2020) bahwa EWOM menyebarkan informasi melalui media online atau Internet, seperti email, blog, ruang obrolan, Facebook, Twitter dan berbagai jenis jejaring sosial lainnya

\section{b. Pelaksanaan}

Setelah akun yang dipilih untuk melakukan endorsement sepakat untuk mau mempromosikan produk, kami memilih beberapa konten berupa gambar produk untuk diposting dan juga caption yang menarik dan cukup dimengerti untuk menarik perhatian para pengikut dari akun yang kami endorse agar mau membeli produk yang kami jual. 


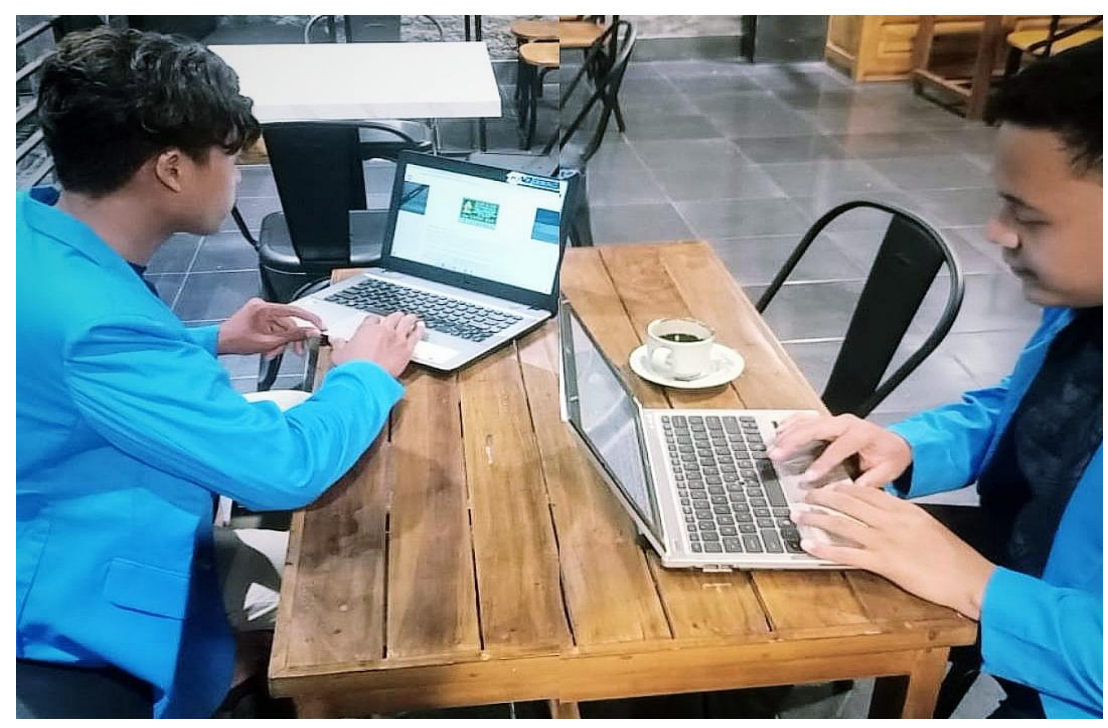

Gambar 6 pembuatan web,istagram,dan Facebook

\section{Endorsment disalah satu akun facebook}

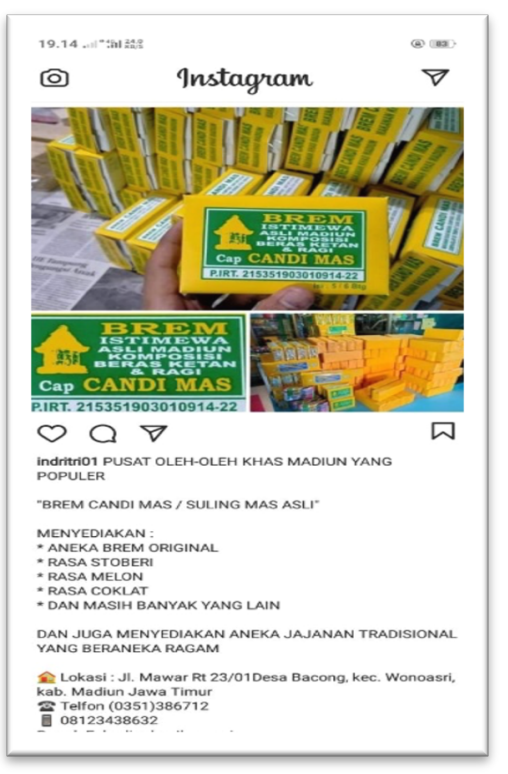

Gambar 7 Endorsement disalah satu akun instagram

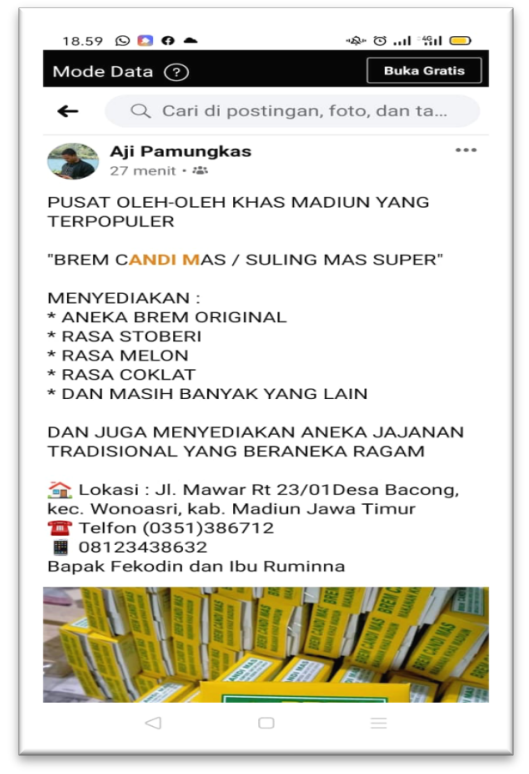

Gambar 8 Endorsment disalah satu akun facebook

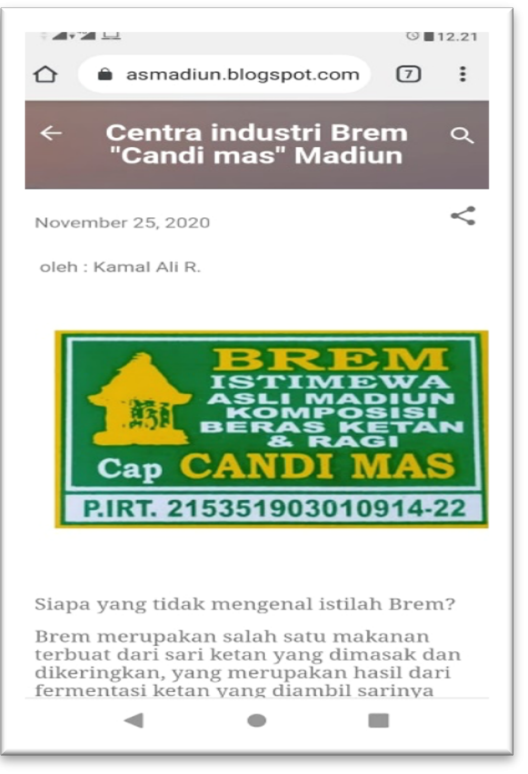

Gambar 9 Pembuatan Blog

\section{Manfaat kegiatan}

a. Mahasiswa

Menambah wawasan tentang UMKM dan diharapkan di masa mendatang dapat menciptakan suatu usaha guna untuk membuka lapangan pekerjaan.

b. Masyarakat

Meningkatkan ketrampilan yang dimiliki untuk menambah penghasilan.

\section{c. Pihak Desa}

Supaya bisa memotivasi guna mendukung berbagai sektor usaha yang ada di masyarakat dan bertujuan untuk mensejahterakan masyarakat sekitar. 


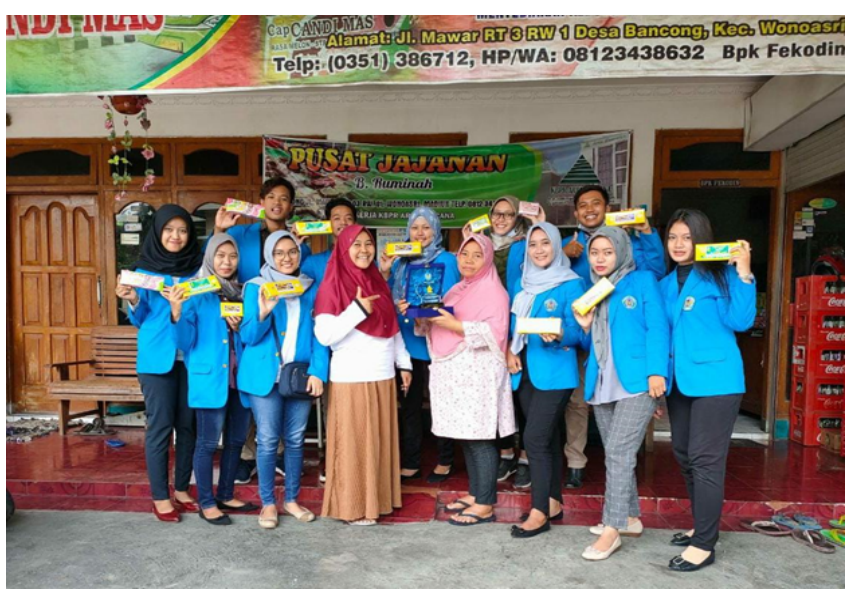

Gambar 10 Foto Bersama Pelaku UMKM Brem

\section{KESIMPULAN DAN SARAN}

Desa Bancong, Kecamatan Wonoasri, Kabupaten Madiun merupakan desa yang mayoritas penduduknya sebagai petani mata pencariannya. Di Desa Bancong sebagian memiliki usaha pembuatan brem. Berawal dari brem merupakan makanan khas madiun dan banyak peminatnya untuk dijadikan oleh oleh dibawa sebagai buah tangan untuk saudara diluar kota akhirnya kami memotivasi untuk mengembangkan usaha brem yang ada ini dengan memasarkan melalui media sosial supaya lebih dikenal banyak orang. Pengembangan pemasaran ini kami berikan dengan maksud agar penjualan brem meningkat, produksi lancar dan menambah penghasilan.

Pemasaran brem tersebut akan dilakukan secara online dan langsung. Pemasaran langsung bisa dilakukan kerjasama dengan toko pusat oleh oleh dan toko di dalam pasar, dengan begitu permintaan brem bisa naik sesuai ramainya pembeli yang ada di toko tersebut. Pemasaran lewat media sosial bisa dengan menggunakan web, instagram atau yang lainnya agar lebih dikenal masyarakat luas, menyadari jaman sekarang banyak yang bermain media sosial maka kita manfaatkan untuk pemasaran lewat media sosial.

Kami berharap program ini dapat menambah pengetahuan, wawasan, meningkatkan penjualan brem, meningkatkan produksi brem, meningkatkan penghasilan serta dapat melestarikan makanan khas asli madiun ini dan tetap menjadi oleh oleh utama yang wajib dibawa. Dalam produksi brem ini diharapkan tetap berjalan dan tidak kalah saing dengan yang lainnya tetap memberikan rasa yang khas dan inovasi yang baik serta menarik supaya berkembang dengan baik. Selain itu, produk unggulan ini bisa bermanfaat bagi masyarakat sekitar terutama masyarakat di Desa Bancong. Kami juga mengharap kritik dan saran apabila dalam penulisan laporan program unggulan ini menemukan banyak kesalahan baik dalam penulisan maupun dalam penyusunan kosa kata bahasa.

\section{Conflict of Interests}

The authors declared that no potential conflicts of interests with respect to the authorship and publication of this article.

\section{DAFTAR PUSTAKA}

Agus S. (2016) Strategi Pengembangan Usaha Kecil Menengah (UKM).Jurnal Administrasi bisnis (JAB).Vol.38 No.01

Arlina, N. (2017) Pengembangan Usaha Mikro Kecil dan Menengah (UMKM) Kota Medan.Abdimas Talenta. Vol 02 No.1-4 
Arman Hj. A, , R. U. A. Fauzi , A. S. A. Ditta, I. Idris , and M. F. M. Yazi, (2020) The Role of Perceived Benefits and Perceived Risks Towards the Consumers' Purchase Intention Via ECommerce: An Evidence From Indonesia, Solid State Technology, vol. 63, no. 2s, pp. 3257 3274

Djutikah, E. Bintarawati, B. D., dan Pattinggi, R. (1998). Pengembangan Proses dan Peralatan Pembuatan Kue dan Minuman Brem dari Buah-buahan Tropis Balai Penelitian dan Pengembangan Industri. Surabaya

Fauzi, R. U. A. (2017).Pengaruh Harga Dan Free Wi-Fi Terhadap Keputusan Pembelian Produk Pada Angkringan Di Kecamatan Karas Kabupaten Magetan, Jurnal Aplikasi Bisnis, vol. 17 No. 2, pp. 62-74, https://doi.org/10.20885/jabis.vol17.iss2.art4

Fauzi, R. U. A (2019).The Role Of Free Wireless Fidelity (Wi-Fi) Service, Food Quality, And Servicescape Toward Customer Satisfaction. Asian journal of social science research volume 2, issue 2

Fauzi, R.U.A (2020). Marketing Strategy Analysis and Product Innovation making added Value Bitter Melon Jurnal Keuangan Dan Bisnis, volume 18(1) 107-115

Fauzi R. U. A. (2021).The Influence of Business Plan Competition and Loan Provision on Nurturing the Spirit of Entrepreneurship Among Students, Advances in Economics, Business and Management Research, volume 161, Proceedings of the Conference on International Issues in Business and Economics Research (CIIBER 2019) pp.188-192, https://dx.doi.org/10.2991/aebmr.k.210121.028

Fauzi, R. U. A. D. C. A. Kadi, R. C. Utomo, L. Dewi, and S. R. Muhtar, (2020). Branding dan Product Inovation Pada Usaha Mikro Kecil Menengah Krupuk Bawang Desa Mrahu Kartoharjo Magetan," Madaniya, vol. 1, no. 1, pp. 1 44-52,.

Fauzi, R. U. A D. C. Ari. Kadi, G. K. S. Ernanda, P. Triwidya,dan S. Adhelia,(2021).Keefektifan Peran Digital Marketing Melalui Media Sosial Dalam Proses Pemasaran Produk Galeri UMKM Ekawira, Kare Madiun,” Indonesia Berdaya, vol. 2 no. 1, pp. 21 - 30

Fauzi, R. U. A., Kadi, D. C. A., Waluyo, W., Zakaria, M. A., Lestari, E., Octavia, N., dan Laksono, N. T. (2021). Internet Marketing Strategi Untuk Meningkatkan Pemasaran Industri Kopiah Desa Temboro Karas Magetan. Jurnal Pengabdian Masyarakat Indonesia, 1(1), 17-24. https://doi.org/10.52436/1.jpmi.5

Hoffman D.L., \& Novak T.P. (1996). Marketing in computer-mediated environments: Conceptual foundations. Journal of Marketing, 60(3), 50-68.

Kadi, D. C. A., R. U. A. Fauzi, dan B. B. Cahyani(2020) Strategi Pemasaran World of Mouth dan Online Dalam Sentra Industri Rumah Abon Ikan Lele di Jiwan Kabupaten Madiun. Journal of Social Responsibility Projects by Higher Education Forum 1(2) 49-52,

https://media.neliti.com/media/publications/184506-ID-studi-kelayakan-usaha-brem-di-desakalia.pdf

https://wismasastra.files.wordpress.com/2018/08/contoh-artikel-pengabdian-masyarakat.pdf https://id.m.wikipedia.org/wiki/Instagram-Facebook 